\title{
Regulation of Immunity to Respiratory Syncytial Virus by Dendritic Cells, Toll-Like Receptors, and Notch
}

\author{
NICHOLAS W. LUKACS, JOOST J. SMIT, MATTHEW A. SCHALLER, \\ and DENNIS M. LINDELL
}

\begin{abstract}
The activation and maintenance of pulmonary viral disease is regulated at multiple levels and determined by the early innate response to the pathogenic stimuli. Subsequent activation events that rely directly and indirectly on the virus itself can alter the development and severity of the ensuing immunopathologic responses. In the present review we outline several interconnected mechanisms that rely on the early recognition of viral nucleic acid for the most appropriate anti-viral immune responses, including TLRs and Notch activation in DCs and T cells. Deviation or persistence of the immune response to respiratory viruses may impact significantly on the severity of the responses. While these mechanisms are likely similar in most respiratory viral infections, this review will focus on findings with respiratory syncytial virus (RSV) infections.
\end{abstract}

\section{INTRODUCTION}

$\mathbf{T}$ HE INDUCTION OF IMMUNE RESPONSES IN THE HOST Often determines the nature and the severity of the ensuing illness during infectious diseases. Studies have shown that patients with severe respiratory viral infections have an increased risk for the development of chronic pulmonary diseases (1-5). A number of respiratory viruses have been implicated in the induction of pulmonary diseases, including infections with rhinovirus, influenza, parainfluenza, and adenovirus. Recent studies in children (6) and adults (7) support this contention as it relates to severe asthma exacerbations. Thus, viral infections not only can directly alter the health of an individual, but may also alter the immune environment within infected tissues and thus allow progression of other chronic responses. Several investigators have focused upon respiratory disease using a model of respiratory syncytial virus (RSV) infection, as this virus has epidemiologic links to the development of chronic airway disease. Recent evidence suggests that RSV has a significant role in elderly patient populations as well as in patients with chronic obstructive pulmonary disease. Whereas RSV is rarely fatal in infants, the impact of RSV on the elderly has only recently begun to be recognized and may be associated with nearly as many deaths as influenza (8). The specific mechanism(s) of immune regulation identified in RSV studies may be relevant to other viral infections that must be recognized and cleared properly or a more pathogenic disease progression could result. This review will address the regulation of cellular immune responses during viral infection that result in the activation of appropriate antiviral responses and focus on immune responses in RSV infection models.

\section{DENDRITIC CELLS AND RECOGNITION OF INFECTIOUS AGENTS}

In order to monitor pathogenic insults at mucosal surfaces a complex network of innate immune cells are positioned within the tissue with the ability to recognize

University of Michigan Medical School, Department of Pathology, Ann Arbor, Michigan. 
microorganisms. The surveillance function can be accomplished by resident macrophages that have the ability to quickly phagocytize bacteria and fungi for clearance prior to colonization, thereby avoiding inappropriate activation of the acquired immune system. The epithelial cell barriers that have been set up also provide a reasonable means of protecting the host from colonization, and upon infection can initiate innate immune signals for the recruitment of additional phagocytic cell populations. However, in the case of viral infections, it is difficult, if not entirely impossible, for the innate immune response to clear the virus without activation of the acquired immune system. Thus, the resident and recruited dendritic cell (DC) becomes a critical link for recognition and transport of the viral stimuli to the draining lymph node for activation of the antiviral, cell-mediated responses. The determining factor for the outcome of the response depends upon how the DCs are activated and in what manner the cells interact with the T cells. In addition, the nature of the resulting acquired immune response likely also depends upon the subsets of DC that are recruited, activated, and participate in the initiation of the viral responses.

The ability to monitor the pulmonary environment for pathogen infection is regulated at several levels. During viral infections the innate immune response has adapted mechanisms of pattern recognition to allow immediate and effective identification of the invading microorganisms. These include the toll-like receptor (TLR) activation pathways, both MyD88-dependent and independent, as well as cytoplasmic triggers that include RIG-I and PKR pathways (9-11). TLR4 was the first to be identified to have an effect in RSV infection via its interaction with the F protein of RSV (12). While controversial (13-15), a number of clinical studies have identified a TLR4 polymorphism associated with susceptibility to severe RSV infection (16-21). A recent study demonstrated that the altered TLR4 protein can confer altered responses in epithelial cells and peripheral blood mononuclear cells (22). In our own studies comparing the response to RSV infection in bone marrow-derived DCs from wild-type versus TLR4-deficient DCs $(\mathrm{C} 3 \mathrm{H} / \mathrm{HeJ})$, an early and significant reduction in chemokine production with no alteration in IL-12 was observed (data not shown). Thus, the role of TLR4 may depend upon the cell type and location of the infection. Other TLR molecules that recognize viral components are found in the endosomal compartment, where viruses uncoat and initially release their nucleic acid prior to replication. Once the nucleic acid begins to replicate in the cytoplasm, the relatively high levels appear to activate cytoplasmic triggers such as RIG-I, which drive strong type I IFN responses (23-25). The expression of TLRs in DC subsets may be defining for their function of monitoring the environment. While myeloid/conventional lineage DCs (cDCs) have a relatively wide range of TLRs, including TLR2, TLR3, TLR4, TLR5, and TLR6, the plasmacytoid DCs (pDCs) primarily express TLR7 and TLR9. Because TLR7 and TLR9 are primary recognition molecules for ssRNA and unmethylated $\mathrm{CpG}$ sequences, the pDC likely plays a prominent role in the initial phases of viral infection for monitoring and eliciting the early responses. The notion that pDCs may play an important role in regulation of the immune response is logical given that the $\mathrm{pDC}$ is the predominant producer of IFN- $\alpha$, a major innate cytokine involved in antiviral immunity (26-28). This has been supported in multiple studies that have demonstrated that the removal of pDCs during viral infections leads to decreased viral clearance and increased immunopathology (29-31). Critical experiments on pDC function initially came after the development of antibodies that could specifically deplete pDCs. Subsequently, the initial experiments for pulmonary responses were performed by depleting pDCs during allergic responses, and demonstrated that in the absence of pDCs the allergic response was greatly enhanced (32). The pDC subset was suggested to have a suppressive response on T-cell activation. Recent studies, however, have indicated that pDCs play multiple roles that include antiviral effects by directly limiting viral replication through the production of type I IFN, as well as providing important immune regulatory functions by directing the phenotype of both the CD4 helper T-cell responses and enhancing the CD8 cytotoxic T-cell responses. Thus, the activation of the onceunderestimated pDC has been demonstrated to have a critical role in determining the direction of the immune response, as well as the severity of virus-induced immune responses. This latter concept was prominently identified in a seminal study using herpes simplex virus infection that demonstrated the necessity of pDC migration into the lymph node for development of the most effective CTL responses by affecting the nature of $\mathrm{CDC}$ activation (31). This latter concept was recently supported in experimental RSV infection by depleting pDCs that led to development of severe pathophysiology and altered immune responses (29). Additional unpublished studies by our laboratory using $\mathrm{TLR}^{-/-}$mice have indicated that TLR7 and pDCs are the primary source of IFN- $\alpha$. The lack of signaling through this pathway alters the immune response to RSV infection (data not shown) in a similar manner as that described with MyD88 ${ }^{-1-}$ animals (33), leading to increased pathogenesis. Together, these studies begin to describe a system in which the pDC subset participates in the overall antiviral immune response in a coordinated effort with the cDC subset.

Myeloid DCs also play a central role in antiviral immunity and have been subdivided in several ways. Most recently the function of this subset may be best defined 
based on the co-stimulatory molecule display and the cytokine production profile. Subsets of cDCs that express high levels of CD40 and CD80, and produce high levels of IL-12 are more efficient for promoting a Th-1 type response, whereas those that express OX40L and lower levels of IL-12 promote a predominantly Th-2 response (24,34-36). The activation of cDCs through specific TLR molecules induces important instructive signals expressed during viral infection, including co-stimulatory molecules (CD40 and CD80) and cytokine responses (IL-12 and type I IFN). Together these signals promote a Th-1-type response. While numerous signals that prompt cDCs to become "Th-2 cell inducers" have been suggested, one airway epithelial cell-derived molecule, TSLP, has aroused the interest of researchers $(37,38)$. TSLP directly activates DCs and promotes Th-2 responses through the expression of OX40, as opposed to other critical co-stimulatory molecules (39). In addition, TSLP promotes the production of CCL17 and CCL22, which preferentially bind to CCR4, a chemokine receptor found at high levels on Th-2 cells $(40,41)$. Thus, the determination of whether cDCs will promote a Th-1- or Th-2-mediated response may be dependent upon the nature of the signal that it receives from the pulmonary environment. In addition, specific signals, such as TSLP versus IFN- $\alpha$, may determine the nature of the immune response, and depend entirely upon the cell population (epithelial cell versus pDC) that supplies the virus-induced cytokines for maturation of the $\mathrm{cDC}$ prior to interaction with the $\mathrm{T}$ cell. Activation within the lymph node in the presence of properly activated pDCs have also been shown to be critical for an appropriate immune response via subsequent $\mathrm{cDC}$ activation (31).

A complex relationship is beginning to develop between the different DC subsets and the regulation of immune responses within the lung that may depend upon how these different APC populations are initially activated. Why is it that RSV drives such a profound and undesirable response compared to other respiratory viruses? This information may be gleaned from the mechanism of how RSV infects cells compared to the other respiratory viruses. The mode of infection of RSV appears to be through either membrane fusion and subsequent release of ssRNA into the cytoplasmic compartment, or through clathrin-mediated endocytosis that was $\mathrm{pH}$-independent, as opposed to entry into the cell via a receptor-mediated endosomic compartment through specific receptors that are $\mathrm{pH}$-dependent $(42,43)$. The ability of RSV to enter the cell directly into the cytoplasm is likely the reason that RIG-I is the primary activation pathway, whereas TLR-induced type I IFN is not produced until later time points of infection, when pH-dependent endosomic events occur (44). Once RSV begins to expand its RNA its components may depend upon autophagy-associated and other mechanisms to activate a number of innate immune pathways that depend upon endosomic entry for the TLR-induced activation events discussed above (45). While the literature at present is not entirely clear in this area, the delay in TLR-mediated activation prior to transport to the endosome may give RSV an advantage due to a delay in TLR-induced mediator production. In fact, a recent study demonstrated that pDCs depend upon autophagy for IFN- $\alpha$ production during viral infections, such as that with VSV, that enter the cell via a cytoplasmic route, whereas those that enter via the endoplasmic compartment do not depend upon autophagy (46). Autophagy pathways may provide a logical way to activate the acquired immune system to facilitate viral clearance, but could also provide a process for dysregulation during chronic or severe disease (47). A better understanding of these activation events may allow additional avenues of therapeutic control during complex disease phenotypes within the lung immune environment, as well as provide additional information that may allow better vaccine design.

\section{ADAPTIVE IMMUNE RESPONSES TO RESPIRATORY SYNCYTIAL VIRUS}

The innate immune response is initiated to quickly protect the host from overwhelming infectious organisms, but can also tailor the adaptive immune response to the invading pathogens. During respiratory viral infections the balance of CD4 and CD8 responses manages the progression of the response. It is now clear that RSV-specific $\mathrm{T}$ cells are both protective and pathogenic. In mice depleted of CD4 and CD8 T cells, RSV persists for several weeks but no overt disease symptoms are observed (48). Individually, both CD4 and CD8 contribute to terminating RSV replication, but often at the cost of significant immunopathology. Some groups have investigated the immune response directed toward specific viral proteins. In studies in which mice were vaccinated with vaccinia vectors containing $\mathrm{F}, \mathrm{G}, \mathrm{N}$, or $\mathrm{M} 2$ protein, Th2-mediated disease only resulted upon challenge in mice primed with the G protein (48-52). Studies demonstrated that while the $\mathrm{F}$ protein primed for both $\mathrm{CD} 4$ and $\mathrm{CD} 8$ responses, the G protein only generated CD4 memory responses. The defective response that resulted in Th-2-mediated disease and eosinophilia could be alleviated by vaccinating mice with a G-protein vaccinia vector that also contained an RSV-specific CD8 epitope. These latter observations may help explain the disastrous vaccination strategy using formalin-fixed RSV that elicits a strong Th-2-mediated disease in vaccinated and infected infants (53). Nearly all vaccination strategies against RSV using killed or fixed virus led to inefficient antiviral immune re- 


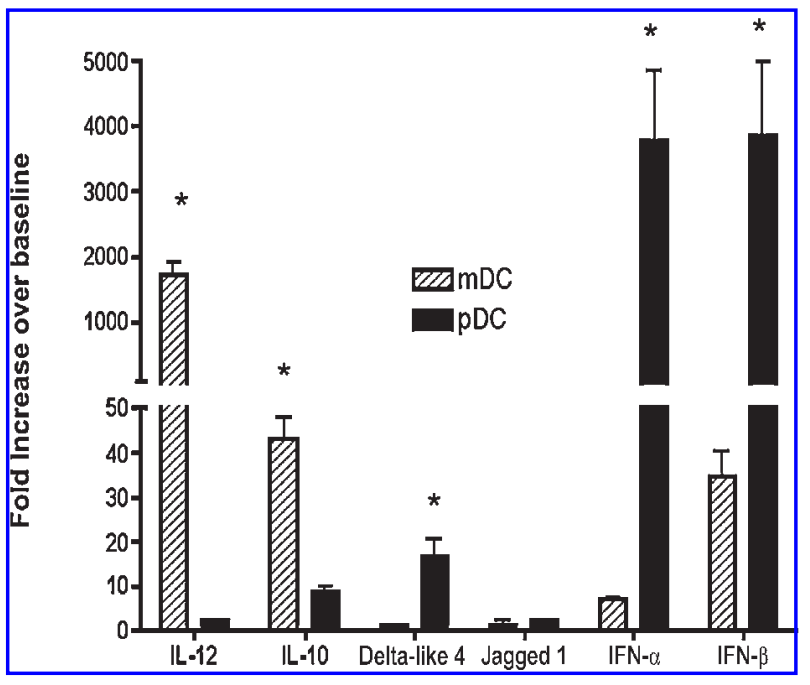

FIG. 1. Peripheral blood mononuclear cells were isolated and $\mathrm{CD}_{1} 4^{+}$myeloid cells were purified and incubated for $6 \mathrm{~d}$ with GM-CSF and IL-4 to induce mDC differentiation. pDCs were isolated directly from the mononuclear cell population. Cells were infected with RSV $($ moi $=1.0)$ and mRNA isolated at $12 \mathrm{~h}$ post-challenge.

sponses and increased immunopathology, and have led researchers to begin examining attenuated live vaccine strains $(54,55)$. Thus, the instructive signals used by DCs to activate $\mathrm{T}$ cells may depend upon live virus to initiate the most appropriate and least pathogenic responses.

While CD8 T cells play a role in viral clearance, previous studies indicate that RSV may impair CD8 T cells that are recruited to the lung. Using MHC class I tetramer staining, lung CD8 T-cell expansion was shown to occur in response to primary RSV infection $(56,57)$. However, when these RSV-specific CD8 T cells were isolated from the lung, they were impaired in their ability to secrete IFN- $\gamma$ and upregulate perforin. Interestingly, depletion of $\mathrm{CD} 8^{+} \mathrm{T}$ cells have led to enhanced $\mathrm{Th}-2$ responses during RSV infection, demonstrating that $\mathrm{CD} 8^{+} \mathrm{T}$ cells may provide important regulatory signals, such as IFN- $\gamma(58)$, suggesting that they may not be defective in all cases. In response to RSV, DCs upregulate co-stimulatory molecules, but may also provide specific factors that regulate the acquired responses. While the mechanisms involved in suppressing the functions of CD8 cells by RSV are unknown and still controversial, these mechanisms may allow for recurrent or persistent infections. In other studies, it has also been shown that DCs co-cultured with RSV have a suppressive effect on IFN- $\gamma$ production by CD4 $\mathrm{T}$ cells in vitro (59). Thus, a multitude of immunoregulatory responses may stem from inappropriate DC activation.

A number of studies have identified that many of the pathophysiologic changes during RSV infection using ex- perimental models relate to the cytokine phenotype that is generated. In particular, the induction of IL-13 appears to be closely associated with several aspects, including airway hyperreactivity, mucus hypersecretion, and excessive inflammation (60-62). Additional studies in humans have linked specific IL-13 as well as IL-4 haplotypes with a preponderance to develop airways disease (63-65). Thus, the distinct activation signals that drive these responses may be governed genetically and not be controlled by the viral infection alone, leaving distinct subsets of patients at substantial risk. In contrast, the generation of the Th- 1 cytotoxic response generally relies on the production of factors such as IL- 12 and IFN- $\alpha / \beta$ from TLR-mediated activation pathways. Pathogen-induced Th-2 responses may preferentially arise in the absence of strong TLR-induced responses that are characterized by low IL-12 levels. Interestingly, studies using cord and peripheral blood from infants that develop severe RSV infections had significantly lower levels of IL-12 production compared to responses in children with mild RSV disease $(66,67)$. This idea is supported by studies that show that MyD88 ${ }^{-/-}$mice, which cannot generate IL-12 in response to viral infection, are incapable of generating Th-1 responses when immunized with complete Freund's adjuvant and ovalbumin (68). RSV infection in MyD88 ${ }^{-/-}$mice generated a predominant Th- 2 response with an accompanying increase in pathogenesis that included eosinophilia and mucus hypersecretion (33). While many of the responses observed during severe RSV infections in patients can be attributed to activation by Th- 2 cytokines, such as eosinophilia and mucus overproduction, others are associated with acute or Th-1-type responses, such as neutrophilia, fever, and weight loss. It is likely that the most severe and prolonged disease phe-

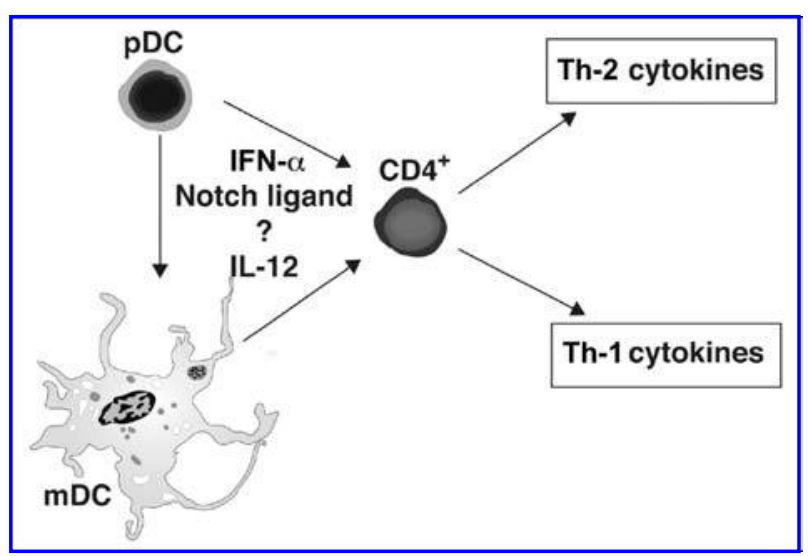

FIG. 2. The activation of the appropriate $\mathrm{CD} 4{ }^{+} \mathrm{T}$-cell responses is most appropriately induced by the interaction with both $\mathrm{pDC}$ and $\mathrm{mDC}$ subsets that each supply important signals for T-cell differentiation. 
notypes are a combination of a complex interaction of both cytokine phenotypes, and both must be considered.

An alternative explanation is that specific pathogens stimulate Th-2 responses through DC receptors and signals that are not fully defined, and it is not merely the absence of Th-1-inducing instructive signals. Recent evidence for this latter possibility comes from studies indicating that expression of the Notch ligands Delta-like and Jagged can provide instructional signals for the development of Th-1 and Th-2 cells, respectively (69).

\section{THE ROLE OF NOTCH AND NOTCH LIGANDS FOR REGULATION OF VIRAL RESPONSES}

Notch family molecules provide an activation network that has been traditionally associated with development, but has also become well known for regulating complex immune responses (69-71). There are four mammalian Notch receptors (Notch1 though Notch 4) with activation pathways that are not fully understood $(70,72,73)$. A key molecule, MAML, is required to recruit co-activators for transcriptional activation by Notch (74-76). In recent years Notch has been shown to be involved in T-cell lineage maturation in the thymus, allowing double negative pro-T cells to mature into double positive $\mathrm{CD} 4 / \mathrm{CD}^{+} \mathrm{T}$ cells (77-79). In the mature immune system the Notch pathway has been described as a signaling mechanism involved in regulating cell lineage choices for $\mathrm{CD}^{+} \mathrm{T}$ cells. Upregulation of the Delta-like Notch ligands in DCs polarized Th-1 cells, whereas the Notch ligand Jagged induced Th- 2 cell polarization (80). Studies have separately demonstrated that Notch activation can be utilized for the generation of Th-1, Th-2, or Treg cell generation, but depends upon additional signals (80-84). Recent studies using genetically altered animals have indicated that Th-2 immune responses are fully dependent upon Notch activation, while Th- 1 responses can develop in the absence of Notch signaling $(85,86)$. In recent studies in our lab we have concentrated on Delta-like 4, which is the primary Notch ligand that is upregulated by RSV infection of DCs (87). When specifically blocking Deltalike 4 in vivo by passive immunization during RSV infection, a more intense pathogenic response including increases in airway hyperreactivity and mucus hypersecretion was observed. The response was characterized by elevated Th- 2 cytokine production that could be reversed in vitro by culturing T cells with rdll4 in re-stimulation studies. Altogether, it appears that the role of notch ligand expression by DCs can differentially regulate the outcome of a viral immune response.

More recently we have also characterized whether there was differential expression of notch ligands by sub- sets of DCs. In particular, we have continued to focus on differences between the expression in $\mathrm{cDCs}$ versus $\mathrm{pDC}$ subsets after RSV infection, as studies have suggested that different DC subsets may differentially express notch ligands (88). Our recent data indicate that when we examine these two DC subsets from human peripheral blood (Fig. 1), we observe that pDCs but not cDCs express a high level of dll4 after RSV infection. Furthermore, when we examine a number of other innate mediators, we find that the pDCs predictably express much higher levels of IFN- $\alpha / \beta$, while the cDCs express significantly more IL-10 and IL-12. Thus, these DC subsets may provide distinct but equally important instructive signals to help differentiate the T-cell-mediated immune responses.

\section{SUMMARY}

Determining how the different subsets of DCs work together to promote the most efficient antiviral response with minimal pathogenesis by driving a Th- 1 versus Th2 cytokine profile (Fig. 2) will be an onerous task for researchers. The generation of the most effective antiviral responses requires multiple directional signals. Without these interacting cues the immune response would be altered and potentially lead to long-term sequelae and persistent pathogenic pulmonary disease. While the relevance of DC, TLRs, and Notch in the activation of the mature immune system is a story that is only beginning, it provides an important concept of how the maturing immune system relies on a diverse set of molecules and cell populations to fine-tune the system for the most appropriate and least pathogenic responses. A better understanding of these and other signals not only will aid in detecting potential patient populations that are at risk, but may offer additional avenues for more informed vaccine strategies.

\section{REFERENCES}

1. Busse WW, Gern JE, and Dick EC: The role of respiratory viruses in asthma. Ciba Found Symp 1997;206:208.

2. Stempel DA, and Boucher RC: Respiratory infection and airway reactivity. Med Clin North Am 1981;65:1045.

3. Hogg JC: Childhood viral infection and the pathogenesis of asthma and chronic obstructive lung disease. Am J

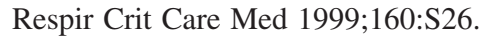

4. Holtzman MJ, Morton JD, Shornick LP, et al.: Immunity, inflammation, and remodeling in the airway epithelial barrier: epithelial-viral-allergic paradigm. Physiol Rev 2002; $82: 19$.

5. Nicholson KG, Kent J, and Ireland DC: Respiratory viruses and exacerbations of asthma in adults. BMJ 1993;307:982. 
6. Zhao J, Takamura M, Yamaoka A, Odajima Y, and Iikura Y: Altered eosinophil levels as a result of viral infection in asthma exacerbation in childhood. Pediatr Allergy Immunol 2002;13:47.

7. Simpson JL, Moric I, Wark PA, Johnston SL, and Gibson PG: Use of induced sputum for the diagnosis of influenza and infections in asthma: a comparison of diagnostic techniques. J Clin Virol 2003;26:339.

8. Thompson WW, Shay DK, Weintraub E, Brammer L, Cox $\mathrm{N}$, Anderson LJ, and Fukuda K: Mortality associated with influenza and respiratory syncytial virus in the United States. JAMA 2003;289:179.

9. Williams BR: Role of the double-stranded RNA-activated protein kinase (PKR) in cell regulation. Biochem Soc Trans 1997;25:509.

10. Carlson CB, Stephens OM, and Beal PA: Recognition of double-stranded RNA by proteins and small molecules. Biopolymers 2003;70:86.

11. Yoneyama M, Kikuchi M, Natsukawa T, et al.: The RNA helicase RIG-I has an essential function in double-stranded RNA-induced innate antiviral responses. Nat Immunol 2004;5:730

12. Kurt-Jones EA, Popova L, Kwinn L, et al.: Pattern recognition receptors TLR4 and CD14 mediate response to respiratory syncytial virus. Nat Immunol 2000;1:398.

13. van der Sluijs KF, van Elden L, Nijhuis M, et al.: Toll-like receptor 4 is not involved in host defense against respiratory tract infection with Sendai virus. Immunol Lett 2003; 89:201.

14. Ehl S, Bischoff R, Ostler T, Vallbracht S, Schulte-Monting J, Poltorak A, and Freudenberg M: The role of toll-like receptor 4 versus interleukin-12 in immunity to respiratory syncytial virus. Eur J Immunol 2004;34:1146.

15. Faisca P, Tran Anh DB, Thomas A, and Desmecht D: Suppression of pattern-recognition receptor TLR4 sensing does not alter lung responses to pneumovirus infection. Microbes Infect 2006;8:621.

16. Tal G, Mandelberg A, Dalal I, et al.: Association between common toll-like receptor 4 mutations and severe respiratory syncytial virus disease. J Infect Dis 2004;189:2057.

17. Mandelberg A, Tal G, Naugolny L, et al.: Lipopolysaccharide hyporesponsiveness as a risk factor for intensive care unit hospitalization in infants with respiratory syncytial virus bronchiolitis. Clin Exp Immunol 2006;144:48.

18. Puthothu B, Forster J, Heinzmann A, and Krueger M: TLR4 and CD14 polymorphisms in respiratory syncytial virus associated disease. Dis Markers 2006;22:303.

19. Rallabhandi P, Bell J, Boukhvalova MS, et al.: Analysis of TLR4 polymorphic variants: new insights into TLR4/MD2/CD14 stoichiometry, structure, and signaling. J Immunol 2006;177:322.

20. Awomoyi AA, Rallabhandi P, Pollin TI, et al.: Association of TLR4 polymorphisms with symptomatic respiratory syn- cytial virus infection in high-risk infants and young children. J Immunol 2007;179:3171.

21. Paulus SC, Hirschfeld AF, Victor RE, Brunstein J, Thomas E, and Turvey SE: Common human toll-like receptor 4 polymorphisms-role in susceptibility to respiratory syncytial virus infection and functional immunological relevance. Clin Immunol 2007;123:252.

22. Tulic MK, Hurrelbrink RJ, Prele CM, et al.: TLR4 polymorphisms mediate impaired responses to respiratory syncytial virus and lipopolysaccharide. J Immunol 2007;179:132.

23. Colonna M: TLR pathways and IFN-regulatory factors: to each its own. Eur J Immunol 2007;37:306.

24. Steinman RM, and Hemmi H: Dendritic cells: translating innate to adaptive immunity. Curr Top Microbiol Immunol 2006;311:17.

25. Kaisho T, and Akira S: Regulation of dendritic cell function through toll-like receptors. Curr Mol Med 2003;3:373.

26. Barchet W, Cella M, and Colonna M: Plasmacytoid dendritic cells-virus experts of innate immunity. Semin Immunol 2005;17:253.

27. Ito T, Wang $\mathrm{YH}$, and Liu YJ: Plasmacytoid dendritic cell precursors/type I interferon-producing cells sense viral infection by toll-like receptor (TLR) 7 and TLR9. Springer Semin Immunopathol 2005;26:221.

28. Fitzgerald-Bocarsly P: Natural interferon-alpha producing cells: the plasmacytoid dendritic cells. Biotechniques 2002;Suppl:16.

29. Smit JJ, Rudd BD, and Lukacs NW: Plasmacytoid dendritic cells inhibit pulmonary immunopathology and promote clearance of respiratory syncytial virus. J Exp Med 2006; 203:1153.

30. Wang H, Peters N, and Schwarze J: Plasmacytoid dendritic cells limit viral replication, pulmonary inflammation, and airway hyperresponsiveness in respiratory syncytial virus infection. J Immunol 2006;177:6263.

31. Yoneyama H, Matsuno K, Toda E, et al.: Plasmacytoid DCs help lymph node DCs to induce anti-HSV CTLs. J Exp Med 2005;202:425.

32. Asselin-Paturel C, Brizard G, Pin JJ, Briere F, and Trinchieri G: Mouse strain differences in plasmacytoid dendritic cell frequency and function revealed by a novel monoclonal antibody. J Immunol 2003;171:6466.

33. Rudd BD, Schaller MA, Smit JJ, et al.: MyD88-mediated instructive signals in dendritic cells regulate pulmonary immune responses during respiratory virus infection. $\mathrm{J} \mathrm{Im-}$ munol 2007; 178:5820.

34. Banchereau J, Paczesny S, Blanco P, Bennett L, Pascual V, Fay J, and Palucka AK: Dendritic cells: controllers of the immune system and a new promise for immunotherapy. Ann NY Acad Sci 2003;987:180.

35. Wilson HL, and O'Neill HC: Murine dendritic cell development: difficulties associated with subset analysis. Immunol Cell Biol 2003;81:239. 
36. de Jong EC, Smits HH, and Kapsenberg ML: Dendritic cell-mediated T cell polarization. Springer Semin Immunopathol 2005;26:289.

37. Liu YJ, Soumelis V, Watanabe N, et al.: TSLP: an epithelial cell cytokine that regulates $\mathrm{T}$ cell differentiation by conditioning dendritic cell maturation. Annu Rev Immunol 2007;25:193.

38. Gilliet M, Soumelis V, Watanabe N, Hanabuchi S, Antonenko S, de Waal-Malefyt R, and Liu YJ: Human dendritic cells activated by TSLP and CD40L induce proallergic cytotoxic T cells. J Exp Med 2003;197:1059.

39. Soumelis V, Reche PA, Kanzler H, et al.: Human epithelial cells trigger dendritic cell mediated allergic inflammation by producing TSLP. Nat Immunol 2002;3:673.

40. Zhou B, Comeau MR, De Smedt T, et al.: Thymic stromal lymphopoietin as a key initiator of allergic airway inflammation in mice. Nat Immunol 2005;6:1047.

41. Ying S, O'Connor B, Ratoff J, et al.: Thymic stromal lymphopoietin expression is increased in asthmatic airways and correlates with expression of Th2-attracting chemokines and disease severity. J Immunol 2005;174:8183.

42. Srinivasakumar N, Ogra PL, and Flanagan TD: Characteristics of fusion of respiratory syncytial virus with HEp-2 cells as measured by R18 fluorescence dequenching assay. J Virol 1991;65:4063.

43. Kolokoltsov AA, Deniger D, Fleming EH, Roberts NJ Jr., Karpilow JM, and Davey RA: Small interfering RNA profiling reveals key role of clathrin-mediated endocytosis and early endosome formation for infection by respiratory syncytial virus. J Virol 2007;81:7786.

44. Liu P, Jamaluddin M, Li K, Garofalo RP, Casola A, and Brasier AR: Retinoic acid-inducible gene I mediates early antiviral response and toll-like receptor 3 expression in respiratory syncytial virus-infected airway epithelial cells. J Virol 2007;81:1401.

45. Iwasaki A: Role of autophagy in innate viral recognition. Autophagy 2007;3:354.

46. Lee HK, Lund JM, Ramanathan B, Mizushima N, and Iwasaki A: Autophagy-dependent viral recognition by plasmacytoid dendritic cells. Science 2007;315:1398.

47. Swanson MS: Autophagy: eating for good health. J Immunol 2006;177:4945.

48. Graham BS, Bunton LA, Wright PF, and Karzon DT: Role of T lymphocyte subsets in the pathogenesis of primary infection and rechallenge with respiratory syncytial virus in mice. J Clin Invest 1991;88:1026.

49. Openshaw PJ, Anderson K, Wertz GW, and Askonas BA: The 22,000-kilodalton protein of respiratory syncytial virus is a major target for Kd-restricted cytotoxic T lymphocytes from mice primed by infection. J Virol 1990;64:1683.

50. Openshaw PJ, Clarke SL, and Record FM: Pulmonary eosinophilic response to respiratory syncytial virus infec- tion in mice sensitized to the major surface glycoprotein G. Int Immunol 1992;4:493.

51. Cherrie AH, Anderson K, Wertz GW, and Openshaw PJ: Human cytotoxic $\mathrm{T}$ cells stimulated by antigen on dendritic cells recognize the $\mathrm{N}, \mathrm{SH}, \mathrm{F}, \mathrm{M}, 22 \mathrm{~K}$, and $1 \mathrm{~b}$ proteins of respiratory syncytial virus. J Virol 1992;66:2102.

52. Alwan WH, and Openshaw PJ: Distinct patterns of T- and B-cell immunity to respiratory syncytial virus induced by individual viral proteins. Vaccine 1993;11:431.

53. Graham BS: Pathogenesis of respiratory syncytial virus vaccine-augmented pathology. Am J Respir Crit Care Med 1995;152:S63.

54. Crowe JE Jr.: Immune responses of infants to infection with respiratory viruses and live attenuated respiratory virus candidate vaccines. Vaccine 1998;16:1423.

55. Dudas RA, and Karron RA: Respiratory syncytial virus

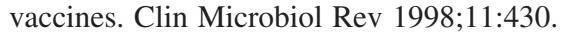

56. Chang J, and Braciale TJ: Respiratory syncytial virus infection suppresses lung CD8 + T-cell effector activity and peripheral CD8 + T-cell memory in the respiratory tract. Nat Med 2002;8:54.

57. Chang J, Srikiatkhachorn A, and Braciale TJ Visualization and characterization of respiratory syncytial virus F-specific CD8(+) T cells during experimental virus infection. J Immunol 2001;167:4254.

58. Hussell T, Baldwin CJ, O'Garra A, and Openshaw PJ: $\mathrm{CD} 8+\mathrm{T}$ cells control Th2-driven pathology during pulmonary respiratory syncytial virus infection. Eur J Immunol 1997;27:3341.

59. de Graaff PM, de Jong EC, van Capel TM, et al.: Respiratory syncytial virus infection of monocyte-derived dendritic cells decreases their capacity to activate CD4 T cells. J Immunol 2005; 175:5904.

60. Lukacs NW, Tekkanat KK, Berlin A, et al.: Respiratory syncytial virus predisposes mice to augmented allergic airway responses via IL-13-mediated mechanisms. J Immunol 2001;167:1060.

61. Tekkanat KK, Maassab HF, Cho DS, et al.: IL-13-induced airway hyperreactivity during respiratory syncytial virus infection is STAT6 dependent. J Immunol 2001;166:3542.

62. Lukacs NW, Moore ML, Rudd BD, et al.: Differential immune responses and pulmonary pathophysiology are induced by two different strains of respiratory syncytial virus. Am J Pathol 2006;169:977.

63. Puthothu B, Krueger M, Forster J, and Heinzmann A: Association between severe respiratory syncytial virus infection and IL13/IL4 haplotypes. J Infect Dis 2006;193:438.

64. Ermers MJ, Hoebee B, Hodemaekers HM, Kimman TG, Kimpen JL, and Bont L: IL-13 genetic polymorphism identifies children with late wheezing after respiratory syncytial virus infection. J Allergy Clin Immunol 2007;119:1086. 
65. You D, Becnel D, Wang K, Ripple M, Daly M, and Cormier SA: Exposure of neonates to respiratory syncytial virus is critical in determining subsequent airway response in adults. Respir Res 2006;7:107.

66. Bont L, Kavelaars A, Heijnen CJ, van Vught AJ, and Kimpen JL: Monocyte interleukin-12 production is inversely related to duration of respiratory failure in respiratory syncytial virus bronchiolitis. J Infect Dis 2000;181:1772.

67. Blanco-Quiros A, Gonzalez H, Arranz E, and Lapena S. Decreased interleukin-12 levels in umbilical cord blood in children who developed acute bronchiolitis. Pediatr Pulmonol 1999;28:175.

68. Su SB, Silver PB, Grajewski RS, Agarwal RK, Tang J, Chan CC, and Caspi RR: Essential role of the MyD88 pathway, but nonessential roles of TLRs 2, 4, and 9, in the adjuvant effect promoting Th1-mediated autoimmunity. J Immunol 2005;175:6303.

69. Dallman MJ, Smith E, Benson RA, and Lamb JR: Notch: control of lymphocyte differentiation in the periphery. Curr Opin Immunol 2005;17:259.

70. McKenzie GJ, Young LL, Briend E, Lamb JR, Dallman $\mathrm{MJ}$, and Champion BR: Notch signalling in the regulation of peripheral T-cell function. Semin Cell Dev Biol 2003; 14:127.

71. Maillard I, Adler SH, and Pear WS: Notch and the immune system. Immunity 2003;19:781.

72. Dallman MJ, Champion B, and Lamb JR: Notch signalling in the peripheral immune system. Novartis Found Symp 2003;252:268.

73. Hoyne GF, Dallman MJ, Champion BR, and Lamb JR: Notch signalling in the regulation of peripheral immunity. Immunol Rev 2001;182:215.

74. Maillard I, Tu L, Sambandam A, et al.: The requirement for Notch signaling at the beta-selection checkpoint in vivo is absolute and independent of the pre-T cell receptor. $\mathbf{J}$ Exp Med 2006;203:2239.

75. Nam Y, Weng AP, Aster JC, and Blacklow SC: Structural requirements for assembly of the CSL.intracellular Notch1.Mastermind-like 1 transcriptional activation complex. J Biol Chem 2003;278:21232.

76. Wu L, Sun T, Kobayashi K, Gao P, and Griffin JD: Identification of a family of mastermind-like transcriptional coactivators for mammalian notch receptors. Mol Cell Biol 2002;22:7688.

77. Schmitt TM, and Zuniga-Pflucker JC: Thymus-derived signals regulate early T-cell development. Crit Rev Immunol 2005;25:141.

78. Harman BC, Jenkinson EJ, and Anderson G: Microenvironmental regulation of Notch signalling in $\mathrm{T}$ cell development. Semin Immunol 2003;15:91.
79. Basson MA, and Zamoyska R: The CD4/CD8 lineage decision: integration of signalling pathways. Immunol Today 2000;21:509.

80. Amsen D, Blander JM, Lee GR, Tanigaki K, Honjo T, and Flavell RA: Instruction of distinct CD4 T helper cell fates by different notch ligands on antigen-presenting cells. Cell 2004;117:515.

81. Rutz S, Mordmuller B, Sakano S, and Scheffold A: Notch ligands Delta-like1, Delta-like4 and Jagged1 differentially regulate activation of peripheral $\mathrm{T}$ helper cells. Eur J Immunol 2005;35:2443.

82. Maekawa Y, Tsukumo S, Chiba S, et al.: Delta1-Notch3 interactions bias the functional differentiation of activated CD4+ T cells. Immunity 2003;19:549.

83. Tu L, Fang TC, Artis D, Shestova O, Pross SE, Maillard I, and Pear WS: Notch signaling is an important regulator of type 2 immunity. J Exp Med 2005;202:1037.

84. Ostroukhova M, Qi Z, Oriss TB, Dixon-McCarthy B, Ray $\mathrm{P}$, and Ray A: Treg-mediated immunosuppression involves activation of the Notch-HES1 axis by membrane-bound TGF-beta. J Clin Invest 2006;116:996.

85. Fang TC, Yashiro-Ohtani Y, Del Bianco C, Knoblock DM, Blacklow SC, and Pear WS: Notch directly regulates gata3 expression during T helper 2 cell differentiation. Immunity 2007;27:100.

86. Amsen D, Antov A, Jankovic D, et al.: Direct regulation of gata3 expression determines the T helper differentiation potential of notch. Immunity 2007;27:89.

87. Schaller MA, Neupane R, Rudd BD, et al.: Notch ligand Delta-like 4 regulates disease pathogenesis during respiratory viral infections by modulating Th2 cytokines. J Exp Med 2007;204:2925.

88. Skokos D, and Nussenzweig MC: CD8-DCs induce IL-12independent Th1 differentiation through Delta 4 Notch-like ligand in response to bacterial LPS. J Exp Med 2007;204: 1525 .

Address reprint requests to: Dr. Nicholas W. Lukacs University of Michigan Medical School 4059 BSRB

109 Zina Pitcher Dr. Ann Arbor, Michigan 48109-2200

E-mail: nlukacs@umich.edu

Received December 21, 2007; accepted February 18, 2008. 